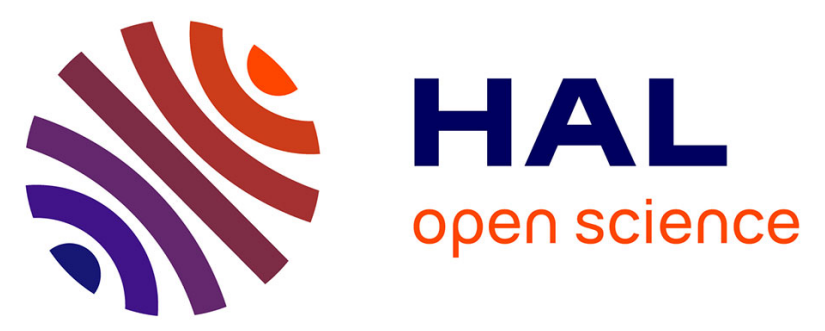

\title{
Comparison of pharmacokinetic variables for creatinine and iohexol in dogs with various degrees of renal function
}

Cécile M Collignon, Reidun Heiene, Yann Queau, Brice S. Reynolds, Amanda J Craig, Didier Concordet, Nathaniel X Harran, Unni Risoen, David Balouka, Mathieu R Faucher, et al.

\section{To cite this version:}

Cécile M Collignon, Reidun Heiene, Yann Queau, Brice S. Reynolds, Amanda J Craig, et al.. Comparison of pharmacokinetic variables for creatinine and iohexol in dogs with various degrees of renal function. American Journal of Veterinary Research, 2012, 73 (11), pp.1841-1847. hal-01191327

\section{HAL Id: hal-01191327 \\ https://hal.science/hal-01191327}

Submitted on 22 Jan 2016

HAL is a multi-disciplinary open access archive for the deposit and dissemination of scientific research documents, whether they are published or not. The documents may come from teaching and research institutions in France or abroad, or from public or private research centers.
L'archive ouverte pluridisciplinaire $\mathbf{H A L}$, est destinée au dépôt et à la diffusion de documents scientifiques de niveau recherche, publiés ou non, émanant des établissements d'enseignement et de recherche français ou étrangers, des laboratoires publics ou privés. 


\title{
Comparison of pharmacokinetic variables for creatinine and iohexol in dogs with various degrees of renal function
}

\author{
Cécile M. Collignon, DVM; Reidun Heiene, DVM, PhD; Yann Queau, DVM; Brice S. Reynolds, DVM; \\ Amanda J. Craig, BVSc, M Vet Clin Studies; Didier Concordet, PhD; Nathaniel X. Harran, DVM; \\ Unni Risøen, MSc; David Balouka, DVM; Mathieu R. Faucher, DVM; Knut A. Eliassen, PhD; \\ Vincent Biourge, DVM, PhD; Hervé P. Lefebvre, DVM, PhD
}

Objective-To compare pharmacokinetics and clearances of creatinine and iohexol as estimates of glomerular filtration rate (GFR) in dogs with various degrees of renal function. Animals - 50 Great Anglo-Francais Tricolor Hounds with various degrees of renal function. Procedures-Boluses of iohexol $(40 \mathrm{mg} / \mathrm{kg})$ and creatinine $(647 \mathrm{mg} / \mathrm{kg})$ were injected IV. Blood samples were collected before administration and 5 and 10 minutes and 1, 2, 4, 6, and 8 hours after administration. Plasma creatinine and iohexol concentrations were assayed via an enzymatic method and high-performance liquid chromatography, respectively. A noncompartmental approach was used for pharmacokinetic analysis. Pharmacokinetic variables were compared via a Bland-Altman plot and an ANOVA.

Results - Compared with results for creatinine, iohexol had a significantly higher mean \pm SD plasma clearance $(3.4 \pm 0.8 \mathrm{~mL} / \mathrm{min} / \mathrm{kg}$ vs $3.0 \pm 0.7 \mathrm{~mL} / \mathrm{min} / \mathrm{kg})$ and a significantly lower mean volume of distribution at steady state $(250 \pm 37 \mathrm{~mL} / \mathrm{kg}$ vs $539 \pm 73 \mathrm{~mL} / \mathrm{kg})$, mean residence time $(80 \pm 31$ minutes vs $195 \pm 73$ minutes), and mean elimination half-life (74 \pm 20 minutes vs $173 \pm 53$ minutes). Despite discrepancies between clearances, especially for high values, the difference was $<0.6 \mathrm{~mL} / \mathrm{min} / \mathrm{kg}$ for $34(68 \%)$ dogs. Three dogs with a low GFR $(<2 \mathrm{~mL} / \mathrm{min} / \mathrm{kg})$ were classified similarly by both methods.

Conclusions and Clinical Relevance-Plasma iohexol and creatinine clearances can be used interchangeably for screening patients suspected of having chronic kidney disease (ie, low GFR), but large differences may exist for dogs with a GFR within or above the reference range. (Am J Vet Res 2012;73:1841-1847)

\begin{abstract}
A ccurate assessment of renal function is required in many clinical settings. Indications for screening of renal function include animals with nonazotemic polyuria or mild increases in plasma creatinine concen-

\footnotetext{
Received July 25, 2011.

Accepted February 29, 2012

From the Unité de recherche clinique (Collignon, Queau, Reynolds, Craig, Harran, Balouka, Faucher, Lefebvre), Ecole nationale vétérinaire de Toulouse (Concordet), Institut national polytechnique de Toulouse, Université de Toulouse, F-31076 Toulouse, France; the Departments of Companion Animal Clinical Sciences (Heiene) and Basic Sciences and Aquatic Medicine (Risøen, Eliassen), Norwegian School of Veterinary Science, Oslo, Norway; Unité mixte de recherches 1331, Institut national de la recherche agronomique, Toxalim, F-31027 Toulouse, France (Concordet); and Research Center, Royal Canin SAS, 30470 Aimargues, France (Biourge). Dr. Queau's present address is Research Center, Royal Canin SAS, 30470 Aimargues, France. Dr. Craig's present address is Department of Small Animal Medicine, Faculty of Veterinary Science, University of Sydney, Sydney, NSW 2006, Australia.

Supported by Royal Canin SAS and the Norwegian Research Council. Presented in abstract form at the 27th Annual Forum of the American College of Veterinary Internal Medicine, Montréal, June 2009.

The authors thank Claude Germain for assistance with the plasma creatinine assays.

Address correspondence to Dr. Lefebvre (h.lefebvre@envt.fr).
}

\begin{tabular}{|c|c|}
\hline & ABbreviations \\
\hline AUC & $\begin{array}{l}\text { Area under the plasma concentration- } \\
\text { versus-time curve }\end{array}$ \\
\hline CKD & Chronic kidney disease \\
\hline GFR & Glomerular filtration rate \\
\hline MRT & Mean residence time \\
\hline PECC & Plasma exogenous creatinine clearance \\
\hline PloxC & Plasma iohexol clearance \\
\hline Vdss & Volume of distribution at steady state \\
\hline
\end{tabular}

tration, breeds with a predisposition to familial renal disease, presurgical or posttreatment monitoring, and dosage adjustment for drugs excreted by the kidneys.

Glomerular filtration rate is considered to be the best overall indicator of renal function. ${ }^{1}$ Urinary clearance methods that involve the use of inulin or creatinine are considered as reference methods for GFR measurement but are tedious and time-consuming for practitioners. Alternatives to urinary clearance methods are plasma clearance methods, which require only IV injection of a bolus of the marker and collection of serial blood samples. Pitfalls surrounding the use of the simpler plasma clearance methods have been reviewed. ${ }^{2}$ 
The most common GFR markers that have been used for such an approach in dogs are creatinine and iohexol. The use of $\mathrm{PECC}^{3,4}$ and PIoxC $\mathrm{C}^{5-7}$ has been validated for GFR estimation in dogs. The PECC and PIoxC have been used in dogs with various clinical conditions or clinical situations. For example, PECC has been used in the evaluation of naturally occurring renal and nonrenal diseases, ${ }^{8}$ CKD secondary to leishmaniasis, ${ }^{9}$ chronic valvular disease, ${ }^{10}$ renal safety of cardiac drugs, ${ }^{11}$ and hypothyroidism ${ }^{12,13}$; PIoxC has been used in the evaluation of pyometra, ${ }^{14}$ experimentally induced heart failure, ${ }^{15}$ and cholecalciferol-induced toxicosis. ${ }^{16}$

Distinct advantages exist for PECC and PIoxC. A major advantage of PECC is that assay of creatinine concentrations is cheap and available in most veterinary practices, which allows immediate analysis. However, there currently is no commercially available formulation for creatinine, which thus restricts the use of PECC to research and academic centers. Assay of iohexol concentrations is more expensive and is performed in only a limited number of laboratories throughout the world.

In addition, PECC and PIoxC have the practical advantages of being plasma clearance methods that have been validated separately against criterion-standard methods (eg, inulin or creatinine clearance).,17 However, to our knowledge, they have not been compared in a large field population of dogs to determine whether PECC and PIoxC can be used interchangeably or whether there is an advantage for one over the other when screening a population of potentially diseased dogs. Discrepancies between the 2 methods could be problematic for screening of patients and when conducting research in canine nephrology. Thus, interpretation of the results could differ vastly on the basis of the marker used.

For the study reported here, our hypothesis was that PECC and PIoxC can be used interchangeably. The primary objective of the study was to compare the plasma clearances of creatinine and iohexol in a population of dogs that were naturally exposed to renal pathogens and had various degrees of renal function. The secondary objective was to compare other pharmacokinetic variables to provide additional information about the disposition of each marker.

\section{Materials and Methods}

Animals-Great Anglo-Francais Tricolor Hounds in a client-owned colony of dogs were used in the study. All were hunting dogs housed in an outdoor kennel in the area of Toulouse in southern France. All dogs were fed the same homemade diet, which was primarily composed of poultry meat. The dogs were vaccinated against canine distemper, hepatitis, parvovirus, and leptospirosis; all dogs received regularly scheduled anthelmintic treatments. The colony was selected for use because of expected wide interindividual variation in renal function at the level where GFR testing often will be clinically indicated (ie, nonazotemic or mildly azotemic dogs at risk for development of CKD).

During the last 5 years preceding the study, the colony had a history of CKD, which caused the death of 9 of 50 (18\%) dogs. The onset of clinical CKD was generally diagnosed when dogs were between 2 and 5 years of age, and most dogs died within 6 months after the initial diagnosis of CKD. The diagnosis of CKD was based on clinicopathologic findings (ie, azotemia, proteinuria, and isosthenuria). Bacterial infections (Leptospira spp and Escherichia coli) were diagnosed in some dogs. Hepatozoonosis (caused by Hepatozoon canis) and babesiosis (attributable to Babesia canis) were also diagnosed in many dogs. Recurrent infections were considered to be a more likely cause of CKD than was a genetic disease. Tick control, more frequent vaccination against leptospirosis, and regularly scheduled water intake during hunting season were recommended.

Assessment of GFR was proposed to identify dogs with subclinical renal impairment. Dogs with renal impairment could subsequently be subjected to a more extensive diagnostic evaluation. The owner provided informed consent for use of the dogs in the study, and the study was performed in accordance with French legal animal welfare regulations.

GFR evaluation-A complete physical examination was performed on each dog shortly before GFR evaluation. A blood sample was collected before the administration of iohexol and creatinine for plasma biochemical and hematologic evaluation.

Creatinine solution ( $80 \mathrm{mg} / \mathrm{mL})$ was prepared the day before testing by dissolving anhydrous creatinine ${ }^{a}$ in distilled water. The solution was sterilized by filtration through a $0.2-\mu \mathrm{m}$ filter and collected in sterile bottles, as previously described. ${ }^{4,18}$ The nominal dose of creatinine was $40 \mathrm{mg} / \mathrm{kg}$ (ie, $0.5 \mathrm{~mL}$ of creatinine solution $/ \mathrm{kg}$ ). A commercially available formulation of iohexol ${ }^{\mathrm{b}}$ was used (647 mg of iohexol/ $\mathrm{mL}$, which corresponded to $300 \mathrm{mg}$ of iodine $/ \mathrm{mL}$ ). The nominal dose of iohexol was $647 \mathrm{mg} / \mathrm{kg}$ (ie, $1 \mathrm{~mL}$ of iohexol solution $/ \mathrm{kg}$ ).

Food was withheld from the dogs overnight. Both solutions were administered between 8:30 Am and 11:00 AM by injection through an indwelling catheter inserted in the right cephalic vein. The iohexol solution was administered first, followed immediately by administration of the creatinine solution. The catheter was then rinsed with 2 to $3 \mathrm{~mL}$ of saline $(0.9 \% \mathrm{NaCl})$ solution and immediately removed. Blood samples ( $2 \mathrm{~mL}$ ) were collected in heparin lithium tubes via direct venipuncture of the left cephalic vein immediately before (time 0 ) and 5 and 10 minutes and 1, 2, 4, 6, and 8 hours after administration. Samples were centrifuged, and plasma was harvested and stored at $-20^{\circ} \mathrm{C}$ until laboratory analysis. Water was available ad libitum throughout the 8-hour blood collection period. Dogs were fed immediately after the 8-hour blood collection period.

Assay of creatinine and iohexol concentrationsAll samples were analyzed for creatinine concentrations within 2 weeks after blood collection and for iohexol concentrations within 3 months after blood collection. This duration of storage was acceptable on the basis of previously published stability data (storage for up to 8 months for creatinine in dogs ${ }^{19}$ and 2 months $^{20}$ and $>1$ yearc for iohexol in humans).

Plasma creatinine assays were performed with an enzymatic method via a dry-slide biochemical analyzer ${ }^{\mathrm{d}}$ at the National Veterinary School of Toulouse. Quality 
control was based on weekly measurement of control solutions $^{\text {e,f }}$ with known concentrations of creatinine (87 and $523 \mu \mathrm{mol} / \mathrm{L}$ ). Repeatability of the assay was estimated via assessment of 10 consecutive replicates of the same batch of control solutions and was $<1 \%$. Within-laboratory imprecision was estimated by use of weekly single measurements of creatinine of the same batch of control solutions for a period of 10 consecutive weeks. It was $3.1 \%$ and $1.6 \%$ for the control solutions with creatinine concentrations of 87 and $523 \mu \mathrm{mol} / \mathrm{L}$, respectively.

Plasma iohexol concentration was determined via high-performance liquid chromatography ${ }^{17}$ at the Norwegian School of Veterinary Science. Plasma standard solutions $(1,10,50,100$, and $250 \mu \mathrm{g}$ of iohexol/mL) were made by diluting the iohexol stock solution $(647 \mathrm{~g} / \mathrm{L}$, which corresponded to $300 \mathrm{~g}$ of iodine/L) with pooled plasma obtained from 10 healthy dogs from which food had been withheld. Protein was removed from samples and standards by the addition of 1 volume of a mixture of acetonitrile and ethanol (1:1 [vol/vol]), after which samples and standards were incubated overnight and then centrifuged at $15,000 \times g$ for 30 minutes. The supernatant was diluted by the addition of 3 volumes of high-performance liquid chromatography-grade water before injection into the chromatograph. All steps were performed at $4^{\circ} \mathrm{C}$. Iohexol consists of 2 stereoisomers, endoiohexol and exoiohexol, with the exoiohexol form yielding the dominant peak. The iohexol concentration was calculated from the height of the exoiohexol absorbance peak, as previously described. ${ }^{17}$
Pharmacokinetic analysis-All analyses were performed with pharmacokinetic software.g Data for plasma iohexol and creatinine concentrations were subjected to noncompartmental analysis via a statistical moment approach. For creatinine, the concentration used for data analysis corresponded to the measured value minus the basal value (ie, plasma concentration at time 0 ). The preinjection value was considered representative of the basal plasma concentration of creatinine, as reported elsewhere. ${ }^{4}$

The AUC was calculated via the trapezoidal rule with extrapolation to infinity by use of the following equation:

$$
\operatorname{AUC}=\sum_{\mathrm{t}=0}^{\mathrm{t}_{\text {last }}}\left(\left[\left\{\mathrm{C}_{\mathrm{n}+1}+\mathrm{C}_{\mathrm{n}}\right\} / 2\right] \cdot\left[\mathrm{t}_{\mathrm{n}+1}-\mathrm{t}_{\mathrm{n}}\right]\right)+\left(\mathrm{C}_{\text {last }} / \lambda_{\mathrm{z}}\right)
$$

where $C_{n}$ and $C_{n+1}$ are the concentrations measured at time $t_{n}$ and $t_{n+1}, C_{\text {last }}$ is the last measured concentration (at time $\mathrm{t}_{\text {last }}$ ), and $\lambda_{\mathrm{z}}$ is the slope of the elimination phase. Plasma clearance of each substance was determined by dividing the dose administered by the AUC. The Vdss, MRT, and elimination half-life were also calculated, as described elsewhere. ${ }^{21}$

Statistical analysis-Statistical analyses were performed with commercially available software. ${ }^{\text {h }}$ Results were expressed as mean \pm SD. Normality of the pharmacokinetic variables was assessed with the KolmogorovSmirnov test. The plasma clearance of iohexol and that of creatinine were compared via a Bland-Altman plot. The difference between PECC and PIoxC was plotted

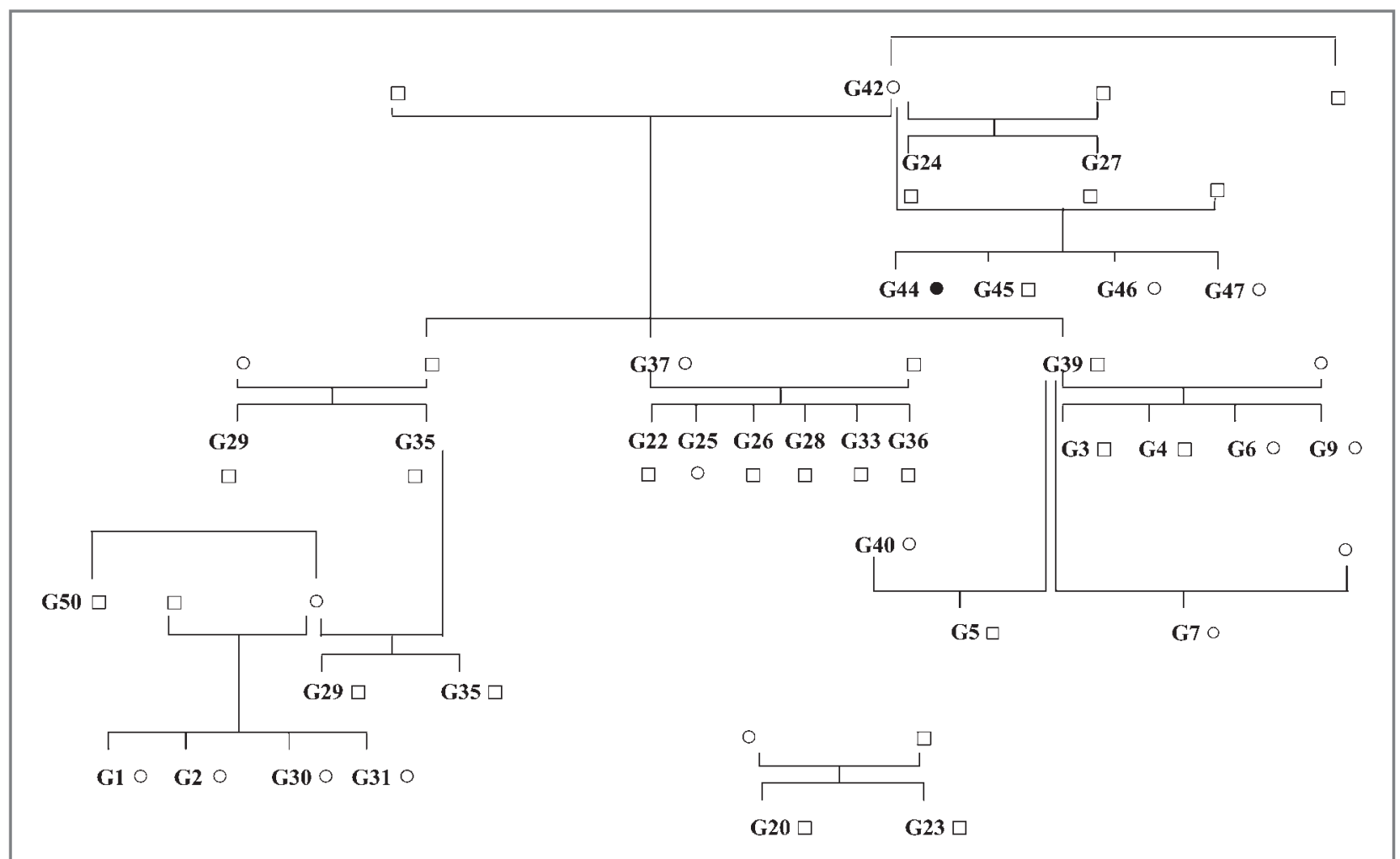

Figure 1-Related dogs among the population of 50 Great Anglo-Francais Tricolor Hounds used for evaluation of GFR via measurement of plasma concentrations of iohexol and creatinine. Thirty-three male (white squares) and female (white circles) dogs (each of which is indicated by a study identifier [eg, G1]) were related, including 1 female dog with a low GFR (black circle). Seventeen dogs, including 2 dogs with a low GFR, were not related to any of the other dogs in the study population and are not indicated here. 
Table 1-Mean \pm SD and range values for plasma variables and PCV in 50 dogs with various degrees of renal function that were used for evaluation of GFR via measurement of plasma concentrations of iohexol and creatinine.

\begin{tabular}{|c|c|c|c|}
\hline Variable & Mean \pm SD & Range & $\begin{array}{c}\text { Reference } \\
\text { interval }\end{array}$ \\
\hline $\begin{array}{l}\text { Glucose }(\mathrm{mmol} / \mathrm{L}) \\
\text { Urea }(\mathrm{mmol} / \mathrm{L}) \\
\text { Creatinine }(\mu \mathrm{mol} / \mathrm{L}) \\
\text { Sodium }(\mathrm{mmol} / \mathrm{L}) \\
\text { Potassium }(\mathrm{mmol} / \mathrm{L}) \\
\text { Chloride }(\mathrm{mmol} / \mathrm{L}) \\
\text { Total calcium }(\mathrm{mmol} / \mathrm{L}) \\
\text { Phosphate }(\mathrm{mmol} / \mathrm{L})\end{array}$ & $\begin{array}{c}5.1 \pm 0.7 \\
4.1 \pm 3.1 \\
75 \pm 22 \\
153 \pm 8 \\
4.7 \pm 0.2 \\
119 \pm 3 \\
2.8 \pm 0.1 \\
1.8 \pm 0.3\end{array}$ & $\begin{array}{c}3.6-6.3 \\
1.2-17.2 \\
55-169 \\
115-163 \\
3.9-5.4 \\
114-125 \\
2.5-3.1 \\
1.3-2.6\end{array}$ & $\begin{array}{c}3.7-8.2 \\
1.6-10.9 \\
44-133 \\
138-148 \\
3.5-5.0 \\
110-118 \\
2.4-3.0 \\
0.7-2.6\end{array}$ \\
\hline $\begin{array}{l}\text { Total protein (g/L) } \\
\text { AST (U/L) } \\
\text { ALT (U/L) } \\
\text { CK (U/L) } \\
\text { ALP (U/L) } \\
\text { Cholesterol (mmol/L) } \\
\text { Triglycerides (mmol/L) } \\
\text { PCV (\%) }\end{array}$ & $\begin{aligned} 73 & \pm 5 \\
30 & \pm 7 \\
37 & \pm 18 \\
93 & \pm 44 \\
103 & \pm 105 \\
5.7 & \pm 1.2 \\
0.3 & \pm 0.09 \\
40 & \pm 5\end{aligned}$ & $\begin{array}{l}62-88 \\
18-50 \\
11-105 \\
44-269 \\
40-761 \\
3.4-10.4 \\
0.1-0.4 \\
29-56\end{array}$ & $\begin{array}{c}48-66 \\
1-47 \\
3-50 \\
24-467 \\
20-155 \\
3.3-9.3 \\
0.2-1.3 \\
37-55\end{array}$ \\
\hline
\end{tabular}

against the mean for the 2 methods. ${ }^{22}$ The effect of the marker on the value of each pharmacokinetic variable, including PECC and PIoxC, was analyzed via an ANOVA. Values of $P<0.05$ were considered significant.

\section{Results}

Animals-Fifty dogs (27 males and 23 females) were included in the study. Thirty-three dogs were related (Figure 1). Mean \pm SD body weight was $34.3 \pm$ $4.9 \mathrm{~kg}$ (range, 24.1 to $44.0 \mathrm{~kg}$ ), and mean age was 3.9 \pm 2.3 years (range, 0.7 to 8.5 years). Physical examination conducted before injection of iohexol and creatinine revealed left basal systolic heart murmur in $1 \mathrm{dog}$, small cutaneous wounds in 5 dogs, and lymph node hypertrophy in 21 dogs. Plasma variables and PCV were determined (Table 1). All dogs had abnormally high total plasma protein concentrations (between 67 and $88 \mathrm{~g} / \mathrm{L}$ ), except for 2 dogs. Four dogs were mildly azotemic. Two dogs had a slight increase in plasma concentrations of both urea (11.6 and $17.2 \mathrm{mmol} / \mathrm{L})$ and creatinine (169 and $140 \mu \mathrm{mol} / \mathrm{L})$. One dog had a slight increase in the plasma creatinine concentration (137 $\mu \mathrm{mol} / \mathrm{L})$, whereas another dog had a slight increase in the plasma urea concentration $(12.8 \mathrm{mmol} / \mathrm{L})$. Activities for alanine aminotransferase and alkaline phosphatase were abnormally high in 4 and 2 dogs, respectively. Other findings were unremarkable.

Pharmacokinetic analysis-The actual mean \pm SD dose of creatinine and iohexol administered was $38 \pm$ $2 \mathrm{mg} / \mathrm{kg}$ and $616 \pm 26 \mathrm{mg} / \mathrm{kg}$, respectively. No adverse effects were noticed after injection of the GFR markers, except for 1 dog that vomited during administration of the iohexol solution. Plasma concentrations of creatinine and iohexol over time were plotted (Figures 2 and 3). The extrapolated part of the AUC represented a mean \pm SD of $10.5 \pm 6.0 \%$ and $1.1 \pm 2.0 \%$ of the total AUC for creatinine and iohexol, respectively. The extrapolated part of the AUC was $<20 \%$ for 46 of 50 creatinine AUCs and for all 50 iohexol AUCs.

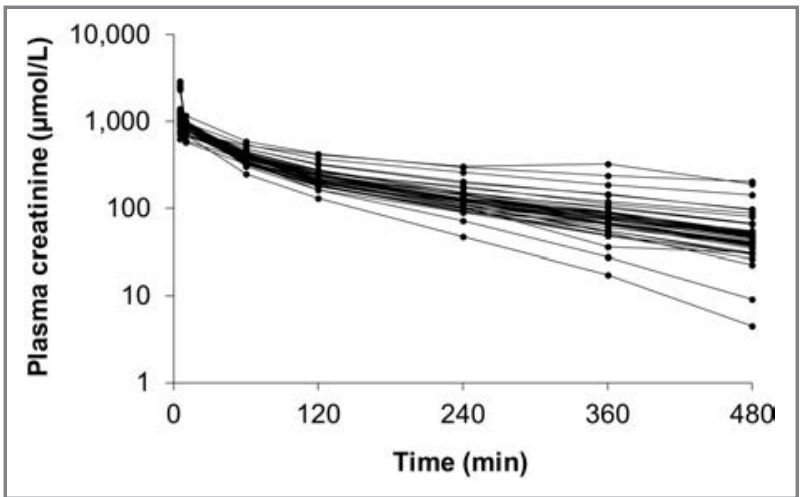

Figure 2-Plasma creatinine concentration after IV administration of a bolus of creatinine $(40 \mathrm{mg} / \mathrm{kg})$ to 50 dogs with various degrees of renal function. Time of injection was designated as time 0 . Plotted creatinine concentrations represent the measured creatinine concentrations minus the basal (time 0 ) plasma creatinine concentration.

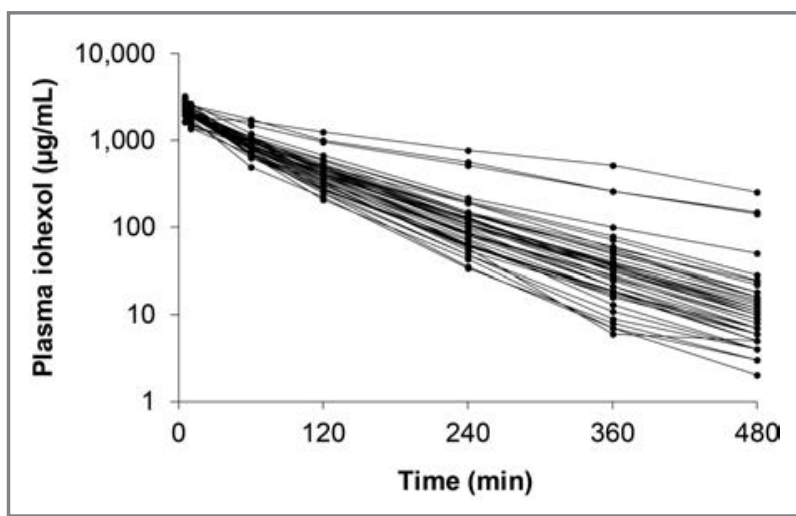

Figure 3-Plasma iohexol concentration after IV administration of a bolus of iohexol $(647 \mathrm{mg} / \mathrm{kg})$ to 50 dogs with various degrees of renal function. Time of injection was designated as time 0 .

Table 2-Pharmacokinetic parameters of creatinine and iohexol after IV bolus administration in 50 dogs.

\begin{tabular}{|c|c|c|c|c|}
\hline \multirow[b]{2}{*}{ Variable } & \multicolumn{2}{|c|}{ Creatinine } & \multicolumn{2}{|c|}{ Iohexol } \\
\hline & Mean \pm SD & Range & Mean \pm SD & Range \\
\hline $\begin{array}{l}\text { Plasma clearance } \\
(\mathrm{mL} / \mathrm{min} / \mathrm{kg})\end{array}$ & e $3.0 \pm 0.7$ & $1.1-5.7$ & $3.4 \pm 0.8$ & $1.2-5.1$ \\
\hline $\begin{array}{l}\text { Vdss (mL/kg) } \\
\text { Elimination } \\
\text { half-life (min) }\end{array}$ & $\begin{array}{l}539 \pm 73 \\
173 \pm 53\end{array}$ & $\begin{array}{r}365-688 \\
74-412\end{array}$ & $\begin{array}{r}250 \pm 37 \\
74 \pm 20\end{array}$ & $\begin{array}{r}179-347 \\
49-166\end{array}$ \\
\hline MRT (min) & $195 \pm 73$ & $84-517$ & $80 \pm 31$ & $46-230$ \\
\hline
\end{tabular}

Pharmacokinetic variables for creatinine and iohexol were determined (Table 2). A significant difference between creatinine and iohexol was detected for plasma clearance $(P=0.001)$, Vdss $(P<0.001)$, elimination half-life $(P<0.001)$, and MRT $(P<0.001)$.

Agreement between PECC and PIoxC was evaluated via a Bland-Altman plot (Figure 4). The number of dogs for which the absolute difference between PIoxC and PECC was $<0.2,<0.4,<0.6,<0.8,<1$, and $>1$ $\mathrm{mL} / \mathrm{min} / \mathrm{kg}$ was determined (Table 3 ). The largest differences between PIoxC and PECC were detected for dogs with a GFR within or above the reference interval.

Three dogs had a PECC and PIoxC $<2 \mathrm{~mL} / \mathrm{min} /$ $\mathrm{kg}$. The PECC and PIoxC for each of these dogs were 


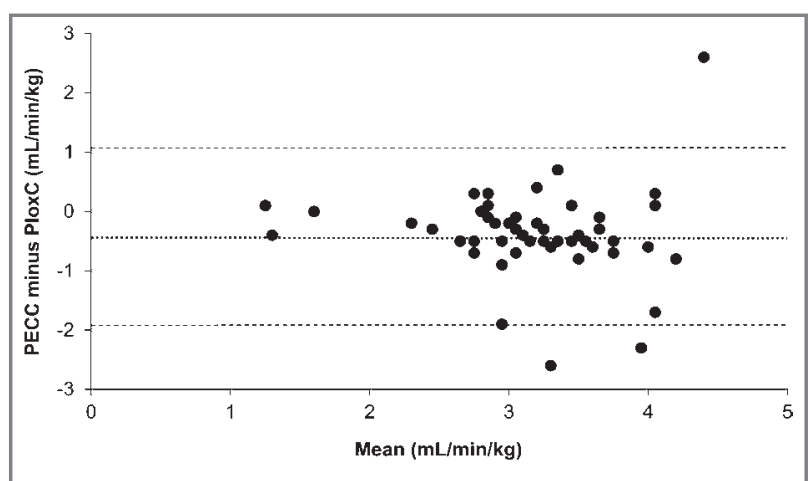

Figure 4-Bland-Altman plot of PECC and PloxC determined in 50 dogs with various degrees of renal function. The x-axis corresponds to the mean value for both methods, whereas the $y$ axis corresponds to the difference between the 2 methods. The mean of the differences between PECC and PloxC (thick dotted line) and the mean \pm 2 SD of the differences between PECC and PloxC (thin dotted lines) are indicated.

Table 3-Cumulative number (percentage) of dogs among the test population ( $n=50$ dogs) on the basis of the absolute difference between PloxC and PECC.

\begin{tabular}{|cr|}
\hline $\begin{array}{l}\text { Absolute difference between } \\
\text { PloxC and PECC (mL/min/kg) }\end{array}$ & No. (\%) of dogs \\
\hline$<0.2$ & $9(18)$ \\
$<0.4$ & $21(42)$ \\
$<0.6$ & $34(68)$ \\
$<0.8$ & $41(82)$ \\
$<1.0$ & $45(90)$ \\
$>1.0$ & $5(10)$ \\
\hline
\end{tabular}

1.3 and $1.2 \mathrm{~mL} / \mathrm{min} / \mathrm{kg}, 1.1$ and $1.5 \mathrm{~mL} / \mathrm{min} / \mathrm{kg}$, and 1.6 and $1.6 \mathrm{~mL} / \mathrm{min} / \mathrm{kg}$, respectively. These 3 dogs were the 2 dogs that had increases in plasma concentrations of both creatinine and urea and the dog with a slight increase in plasma creatinine concentration. The dog with an increase in the plasma urea concentration had a PECC and PIoxC of 4.1 and $4.0 \mathrm{~mL} / \mathrm{min} / \mathrm{kg}$, respectively.

\section{Discussion}

The main conclusion for the study reported here was that PECC and PIoxC provided different GFR estimates but can be used interchangeably to screen dogs with subclinical renal impairment. Additionally, this study was an example of the usefulness of practical methods for GFR estimation in a clinical situation. An advantage of this study was that a relatively large population of dogs with various degrees of renal function was used for the kinetic evaluations simultaneously via the same standardized conditions.

The most common clinical finding was lymph node hypertrophy. In the authors' experience, it is a common finding in such hunting dogs. These dogs go through bushes during hunting, and skin wounds are frequent (detected here in 5 dogs); these wounds generate local inflammation and infection and therefore some degree of lymphadenomegaly. Lymph nodes may also become enlarged during systemic infectious diseases, especially those induced by vector-borne pathogens. ${ }^{23}$ It is common for hunting dogs in southern France to be infested with ticks. Moreover, infections from unknown sources that possibly contributed to the clinical signs cannot be excluded.
The striking pathological finding was an abnormally high plasma protein concentration in 48 dogs. The cause is unknown. Dehydration was unlikely because it was not clinically detected in any tested dog and the PCV was not elevated. Unfortunately, serum protein electrophoresis was not performed in the present study. High plasma protein concentrations could be explained by hyperglobulinemia. Increased globulin concentrations have been reported in animals with chronic inflammatory and infectious diseases (typically $\gamma$-globulins) but also in animals with nephrotic syndrome ( $\alpha_{2}$ - and $\beta$-globulins). ${ }^{24}$ High plasma protein concentrations could also be a breed-specific characteristic of Great Anglo-Francais Tricolor Hounds.

The mean difference between PIoxC and PECC was $0.4 \mathrm{~mL} / \mathrm{min} / \mathrm{kg}$; PECC was $12 \%$ lower than PIoxC. These results differ from those reported in cats because PECC was 35\% higher than the PIoxC in healthy cats ${ }^{25,26}$ and cats with renal disease. ${ }^{25}$ However, in a study ${ }^{27}$ that involved the use of a limited sampling strategy in 57 cats, the difference between PECC and PIoxC was only $13 \%$, which is quite similar to the value detected in the present study. The percentage of dogs that had a difference between PIoxC and PECC $<0.6 \mathrm{~mL} / \mathrm{min} / \mathrm{kg}$ (ie, $<18 \%$ ) was $68 \%$. Only $10 \%$ of the dogs with a GFR within or above the reference interval had values with a difference $>1 \mathrm{~mL} / \mathrm{min} / \mathrm{kg}$ (corresponding to a difference between PECC and PIoxC of $>30 \%$ ). Of clinical relevance, for the 3 dogs with a GFR $<2 \mathrm{~mL} / \mathrm{min} / \mathrm{kg}$ (corresponding to the cutoff value used by other authors for iohexol ${ }^{28}$ and creatinine ${ }^{10,12,13}$ ), the differences between PECC and PIoxC were $0.1,0.4$, and $0 \mathrm{~mL} / \mathrm{min} /$ $\mathrm{kg}$, respectively, and thus of minor importance for patient classification.

A limitation of the present study was that systemic blood pressure was not measured because it was conducted in a field setting and not as an in-hospital study. Another limitation of this study was the relatively small number of dogs with low clearance values. Potential differences between the markers may be more evident in a larger population of dogs with reduced renal function. Another potential limitation of the study was that marker-specific reference intervals were not used, as has been reported in cats. ${ }^{27}$ In dogs, reference values for GFR estimates are dependent on body weight. For PIoxC, a lower cutoff value of $1.2 \mathrm{~mL} / \mathrm{min} / \mathrm{kg}$ has been proposed for dogs with a body weight of 32 to $70.3 \mathrm{~kg},{ }^{29}$ with an upper limit of the 95\% confidence interval of $1.5 \mathrm{~mL} / \mathrm{min} / \mathrm{kg}$. For PECC, the cutoff value proposed was $1.7 \mathrm{~mL} / \mathrm{min} / \mathrm{kg}$ for dogs with a body weight of 25 to $45 \mathrm{~kg}$. ${ }^{\mathrm{i}}$ However, the reference populations of those 2 studies $^{29, i}$ did not include Great Anglo-Francais Tricolor Hounds. The 3 dogs that had a clearance $<2 \mathrm{~mL} / \mathrm{min} /$ $\mathrm{kg}$ would have been considered to have an abnormal GFR for PECC and abnormal or borderline abnormal GFR for PIoxC by use of the published marker-specific reference intervals.

Values of PECC and PIoxC differed, especially when GFR was within or above the reference interval. These discrepancies between the 2 methods are difficult to explain. An extrapolated portion $>20 \%$ of the total AUC for creatinine kinetics was used for the 3 dogs with a low GFR (PECC and PIoxC $<2 \mathrm{~mL} / \mathrm{min} / \mathrm{kg}$ ) and 
another dog for which PECC and PIoxC were 2.2 and $2.4 \mathrm{~mL} / \mathrm{min} / \mathrm{kg}$, respectively. Therefore, extrapolation of AUC cannot explain the observed differences. Differences of this magnitude between PECC and PIoxC are commonly described in studies ${ }^{2}$ conducted to compare GFR markers. The PECC was $17 \%$ and 3\% higher, when compared with urine exogenous creatinine and inulin clearance, respectively. ${ }^{4}$ The mean PIoxC-to-urine creatinine clearance ratio was 1.05 in 1 study. ${ }^{7}$ In another study ${ }^{17}$ in which the variation in renal function of 43 dogs was similar to that of the present study, plasma clearance of iohexol was lower (mean, $0.24 \mathrm{~mL} / \mathrm{min} / \mathrm{kg}$ lower) than plasma clearance of inulin. Differences in physiologic renal processing of creatinine and iohexol cannot be excluded. Weak excretion of creatinine by the renal tubules has been reported in male dogs, ${ }^{30}$ but the authors of 2 subsequent studies ${ }^{4,31}$ suggested that it was negligible. If there were such secretion, PECC would be higher than that of iohexol.

Results for other pharmacokinetic variables may be helpful for understanding differences in the disposition of each marker. A noncompartmental approach was used in the present study because it is an assumption-free method, which is in contrast to compartmental analysis. The Vdss, MRT, and elimination half-life of creatinine were 2.2- to 2.4-fold as high as those of iohexol. Similar findings have been reported in cats, with Vdss, MRT, and elimination half-life of creatinine being 3.0-, 2.3-, and 2.4-fold as high as those of exoiohexol, respectively. ${ }^{25}$ The Vdss of creatinine for the study reported here was extremely close to that reported in other studies, ${ }^{48,32}$ (ie, approx $600 \mathrm{~mL} / \mathrm{kg}$ ) and to the volume of total body water. ${ }^{32, j}$ In contrast, the Vdss of iohexol was close to that of extracellular fluid volume. ${ }^{33}$ Elimination of creatinine from the body is slower than the elimination of iohexol, as illustrated by an MRT and elimination half-life of creatinine that are 2.4-fold as high.

The MRT and elimination half-life are hybrid variables that depend on both clearance and Vdss. The difference in the present study for MRT and elimination half-life between creatinine and iohexol was mainly attributable to a creatinine Vdss that was 2.2-fold as high, which indicated that elimination half-life (or MRT) cannot be used as an indicator of plasma clearance. Because of the slower elimination of creatinine, the time point for termination of sample collection is crucial to avoid having to extrapolate too much of the AUC, as has been reported in cats. ${ }^{34}$ Ideally, the extrapolated portion of the AUC should represent $<20 \%$ of the total AUC. This was not the case for creatinine kinetics in 4 dogs in the present study. The time of collection of the last blood sample for creatinine measurement has to be later than that for iohexol measurement. For azotemic dogs with expected renal dysfunction, collection of the last blood sample for creatinine kinetics at 10 hours would be appropriate, as previously proposed. ${ }^{4}$ In practice, GFR estimation is usually not indicated in severely azotemic dogs in which a reduced GFR is already known on the basis of a high plasma creatinine concentration. Thus, for most purposes, sample collection until 8 to 10 hours for creatinine measurement and 4 to 5 hours for iohexol measurement will provide sufficiently accurate estimates of GFR.
For the present study, we concluded that PECC and PIoxC can be used interchangeably for screening patients with suspected CKD. When GFR is low, the differences between the methods are small. However, because of differences between clearances of the markers, it is recommended to use the same marker for repeated measurements when monitoring renal function over time and to use marker-specific reference intervals.

a. Sigma-Aldrich Inc, St Louis, Mo.

b. Omnipaque, Amersham Health, GE Healthcare, Oslo, Norway.

c. Jacobsen PB, Nycomed Imaging AS, Oslo, Norway: Personal communication, 2011.

d. Vitros 250 chemistry system, Ortho-Clinical Diagnostics, Raritan, NJ.

e. Performance Verifier I control serum, Ortho-Clinical Diagnostics, Issy-Les-Moulineaux, France.

f. Performance Verifier II control serum, Ortho-Clinical Diagnostics, Issy-Les-Moulineaux, France.

g. WinNonlin, version 5.2, Scientific Consulting Inc, Apex, NC.

h. Systat, version 8.0, SPSS Inc, Chicago, Ill.

i. Lefebvre HP, Jeunesse E, Concordet D, et al. Assessment of glomerular filtration rate using plasma exogenous creatinine clearance test: preliminary results in a healthy canine population (abstr). J Vet Intern Med 2004;18:415.

j. Lefebvre HP, Bargues I, Biourge V. Volume of distribution of creatinine: an indicator of body water content (abstr). J Vet Intern Med 2011;25:732.

\section{References}

1. Heiene R, Lefebvre HP. Assessment of renal function. In: Elliott J, Grauer GF, eds. BSAVA manual of canine and feline nephrology and urology. 2nd ed. Gloucester, England: British Small Animal Veterinary Association, 2007;117-125.

2. Heiene R, Moe L. Pharmacokinetic aspects of measurement of glomerular filtration rate in the dog: a review. J Vet Intern Med 1998;12:401-414.

3. Labato MA, Ross LA. Plasma disappearance of creatinine as a renal function test in the dog. Res Vet Sci 1991;50:253-258.

4. Watson AD, Lefebvre HP, Concordet D, et al. Plasma exogenous creatinine clearance test in dogs: comparison with other methods and proposed limited sampling strategy. J Vet Intern Med 2002;16:22-33.

5. Moe L, Heiene R. Estimation of glomerular filtration rate dogs with 99M-Tc-DTPA and iohexol. Res Vet Sci 1995;58:138143.

6. Brown SA, Finco DR, Boudinot DF, et al. Evaluation of a single injection method, using iohexol, for estimating glomerular filtration rate in cats and dogs. Am J Vet Res 1996;57:105-110.

7. Finco DR, Braselton WE, Cooper TA. Relationship between plasma iohexol clearance and urinary exogenous creatinine clearance in dogs. J Vet Intern Med 2001;15:368-373.

8. Wehner A, Hartmann K, Hirschberger J. Associations between proteinuria, systemic hypertension and glomerular filtration rate in dogs with renal and non-renal diseases. Vet Rec 2008;162:141-147.

9. Cortadellas O, Fernández del Palacio MJ, Talavera J, et al. Glomerular filtration rate in dogs with leishmaniasis and chronic kidney disease. J Vet Intern Med 2008;22:293-300.

10. Nicolle AP, Chetboul V, Allerheiligen T, et al. Azotemia and glomerular filtration rate in dogs with chronic valvular disease. $J$ Vet Intern Med 2007;21:943-949.

11. Chetboul V, Lefebvre HP, Sampedrano CC, et al. Comparative adverse cardiac effects of pimobendan and benazepril monotherapy in dogs with mild degenerative mitral valve disease: a prospective, controlled, blinded, and randomized study. J Vet Intern Med 2007;21:742-753.

12. Gommeren K, van Hoek I, Lefebvre HP, et al. Effect of thyroxine supplementation on glomerular filtration rate in hypothyroid dogs. J Vet Intern Med 2009;23:844-849.

13. Panciera DL, Lefebvre HP. Effect of experimental hypothyroid- 
ism on glomerular filtration rate and plasma creatinine concentration in dogs. J Vet Intern Med 2009;23:1045-1050.

14. Heiene R, Moe L. The relationship between some plasma clearance methods for estimation of glomerular filtration rate in dogs with pyometra. J Vet Intern Med 1999;13:587-596.

15. Mathieu M, Motte S, Ray L, et al. Effects of ramipril on renal function during progressive overpacing-induced heart failure in dogs. Am J Vet Res 2006;67:1236-1243.

16. Rumbeiha WK, Fitzgerald SD, Kruger JM, et al. Use of pamidronate disodium to reduce cholecalciferol-induced toxicosis in dogs. Am J Vet Res 2000;61:9-13.

17. Heiene R, Eliassen KA, Risøen U, et al. Glomerular filtration rate in dogs as estimated via plasma clearance of inulin and iohexol and use of limited-sample methods. Am J Vet Res 2010;71:1100-1107.

18. Finco DR. Measurement of glomerular filtration rate via urinary clearance of inulin and plasma clearance of technetium Tc $99 \mathrm{~m}$ pentetate and exogenous creatinine in dogs. Am J Vet Res 2005;66:1046-1055.

19. Thoresen SI, Tverdal A, Havre G, et al. Effects of storage time and freezing temperature on clinical chemical parameters from canine serum and heparinized plasma. Vet Clin Pathol 1995;24:129-133.

20. Lee SY, Chun MR, Kim DJ, et al. Determination of iohexol clearance by high-performance liquid chromatography-tandem mass spectrometry (HPLC-MS/MS). J Chromatogr B Analyt Technol Biomed Life Sci 2006;839:124-129.

21. Gibaldi M, Perrier D. Noncompartmental analysis based on statistical moment theory. In: Gibaldi M, Perrier D, eds. Pharmacokinetics. 2nd ed. New York: Marcel Dekker, 1982;409-417.

22. Bland JM, Altman DG. Statistical methods for assessing agreement between two methods of clinical measurement. Lancet 1986;1:307-310.

23. de Caprariis D, Dantas-Torres F, Capelli G, et al. Evolution of clinical, haematological and biochemical findings in young dogs naturally infected by vector-borne pathogens. Vet Microbiol 2011;149:206-212.
24. Eckersall P. Proteins, proteomics, and the dysproteinemias. In: Kaneko JJ, Harvey JW, Bruss ML, eds. Clinical biochemistry of domestic animals. 6th ed. Burlington, Mass: Academic Press, 2008;117-156.

25. Le Garreres A, Laroute V, De La Farge F, et al. Disposition of plasma creatinine in non-azotaemic and moderately azotaemic cats. J Feline Med Surg 2007;9:89-96.

26. van Hoek I, Vandermeulen E, Duchateau L, et al. Comparison and reproducibility of plasma clearance of exogenous creatinine, exo-iohexol, endo-iohexol, and 51Cr-EDTA in young adult and aged healthy cats. J Vet Intern Med 2007;21:950-958.

27. Heiene R, Reynolds BS, Bexfield NH, et al. Estimation of glomerular filtration rate via 2- and 4-sample plasma clearance of iohexol and creatinine in clinically normal cats. Am J Vet Res 2009; 70:176-185.

28. Gleadhill A. Evaluation of screening tests for renal insufficiency in the dog. J Small Anim Pract 1994;35:391-396.

29. Bexfield NH, Heiene R, Gerritsen RJ, et al. Glomerular filtration rate estimated by 3-sample plasma clearance of iohexol in 118 healthy dogs. J Vet Intern Med 2008;22:66-73.

30. Robinson T, Harbison M, Bovee KC. Influence of reduced renal mass on tubular secretion of creatinine in the dog. Am J Vet Res 1974;35:487-491.

31. Finco DR, Tabaru H, Brown SA, et al. Endogenous creatinine clearance measurement of glomerular filtration rate in dogs. Am J Vet Res 1993;54:1575-1578.

32. Greenberg J, Schwartz IL, Spinner M, et al. Apparent volume of distribution of p-aminohippurate and creatinine in the dog. Am J Physiol 1952;168:86-92.

33. Hankes GH, Nelson AW, Swan H. Chlorine-36 as a continuing indicator of extracellular fluid volume in the dog. Am J Vet Res 1973;34:221-229

34. van Hoek IM, Lefebvre HP, Paepe D, et al. Comparison of plasma clearance of exogenous creatinine, exo-iohexol, and endoiohexol over a range of glomerular filtration rates expected in cats. J Feline Med Surg 2009;11:1028-1030. 